\title{
Fundal Placenta Percreta Presenting as Acute Abdomen: A Case Report and the Role of CT-scan in Management
}

\author{
Mohamad K Ramadan, MBBCh-FACS ${ }^{1,2}$, Bassam Sammak, MD, FRCR ${ }^{3}$, Amani Mohsen, MD ${ }^{1}$, Haneen \\ Hijazi, $M D^{1}$ and Dominique A Badr, MD ${ }^{2,4^{*}}$
}

\author{
${ }^{1}$ Department of Obstetrics and Gynecology, Rafic Hariri University Hospital, Lebanon \\ 2Department of Obstetrics and Gynecology, Lebanese University, Lebanon \\ ${ }^{3}$ Director of Diagnostic Imaging Department, Rafic Hariri University Hospital, Lebanon \\ ${ }^{4}$ Department of Obstetrics and Gynecology, Brugmann University Hospital, Belgium
}

*Corresponding author: Dominique A Badr, MD, Department of Obstetrics and Gynecology, Brugmann University Hospital, Place Jean Gabin 6/box 8, Jette 1090, Brussel, Belgium, Tel: +32486172228

\begin{abstract}
Fundal abnormally invasive placentae (AIP) rate is not precisely known, though, it is thought to be infrequent. Acute abdomen due to uterine rupture is an atypical and an extremely rare presentation. Hereby, we report the case of a 33-year-old G3P2002 who presented at 21-weeks with acute abdomen. CT-Scan and color-Doppler ultrasound showed massive hemoperitoneum with a fundal placenta actively bleeding into the abdominal cavity. At laparotomy, the uterus had a $3 \mathrm{~cm}$ dent in its left fundal area through which villi were protruding and actively bleeding. Uterine rupture due to non-previa AIP should be considered in the differential diagnosis of pregnant patients presenting to ED with acute abdomen. Current strategies of referring only patients with placenta previa or placentas covering previous cesarean scars for screening by expert sonographers will not enable prenatal identification of this uncommon yet dangerous AIP.
\end{abstract}

\section{Keywords}

Abnormally invasive placentation, Acute abdomen, CTscan, Massive hemoperitoneum, Non-previa placenta

\section{Introduction}

Abnormally invasive placenta (AIP) refers to abnormal invasion of placental villi into the myometrium due to deficient decidua basalis [1]. General practice consist of screening this condition in high-risk patients who have low-lying placenta (previa) covering a previous cesarean scar, and confirm it later in the third trimester by ultrasound or MRI [2-4]. Nevertheless, placentae located in the uterine fundus can be an AIP. Unfortunately, most of these cases are not diagnosed prenatally and are encountered in the postpartum period as retained placentae and hemorrhage at attempts of manual removal or infrequently might present in the antenatal period as acute abdomen due to uterine rupture and hemorrhagic shock [5]. This is a serious and challenging condition which requires proper instant diagnosis and prompt management. Hereby, we report a case of fundal AIP who presented with acute abdomen at 21 weeks' gestation and describe the findings of Computed Tomography scan (CT-scan) and ultrasonography. A brief review of recent literature was also done to underscore the importance of prenatal diagnosis.

\section{Case Report}

A 33-year-old woman, G3P2002, presented to the emergency department (ED) at 21 weeks of gestation complaining of acute diffuse abdominal pain of 1 day duration. She had a history of 2 previous uncomplicated low segment transverse cesarean delivery (CD). During this pregnancy, she was regularly followed at a private clinic with reportedly smooth antenatal course, normal fetal morphology scan and a placenta located high at the fundus of uterus. Clinical examination revealed an 
apprehensive but pale patient with diffuse abdominal tenderness, rebound tenderness, guarding, and generalized dullness. Vital signs showed tachycardia of 120 beats per minute, tachypnea of 20 breaths per minute, a blood pressure of $100 / 60 \mathrm{mmHg}$, and a temperature of $36.7^{\circ} \mathrm{C}$. Intravenous fluid therapy was started. Laboratory tests showed a hemoglobin of $7.3 \mathrm{~g} / \mathrm{dl}$, marked leukocytosis of 27,000 cells $/ \mathrm{mm}^{3}$, creatinine of $1.3 \mathrm{mg} /$ $\mathrm{dl}$, and normal liver function tests.

A Computed Tomography scan (CT-scan) was done by the ED team to rule out common and serious causes of acute abdomen. It showed a moderate amount of free fluid in the abdomen, a $2 \times 2 \mathrm{~cm}$ exophytic vascular mass bulging through the left fundal area where the placenta was located with indentation of the adjacent myometrium suggestive of placenta percreta (Figure 1). Following these findings, the obstetrical team was urgently consulted. A rapid assessment with a bed-side ultrasound showed an intrauterine fetal death and a fundal placenta with adjacent myometrial thinning. Using color-flow Doppler, an eccentric spurting vessel at the outer border of the uterus was seen jetting blood into the peritoneal cavity. A vaginal exam showed a fully dilated cervix. A decision to perform an urgent laparotomy to control the bleeding was made. Unexpectedly, the patient vaginally delivered a dead macerated male fetus weighing 575 grams on the operative room table. At laparotomy, about 4 liters of fresh blood and clots were evacuated. Exploration of the abdomen showed a $3 \times 2 \mathrm{~cm}$ of the placenta bulging through a dent in the left parasagittal anterior surface of the uterine fundus with active bleeding. Hysterectomy was performed to secure hemostasis. Intraoperatively, the patient received a total of 8 units of packed red cells and 4 units of fresh frozen plasma. She was transferred to the intensive care unit for close observation. Finally, she was discharged home on the third postoperative day in a stable condition. Histopathologic examination confirmed the diagnosis of placenta percreta.

\section{Conclusion}

Placenta previa and CD are the strongest risk fac-
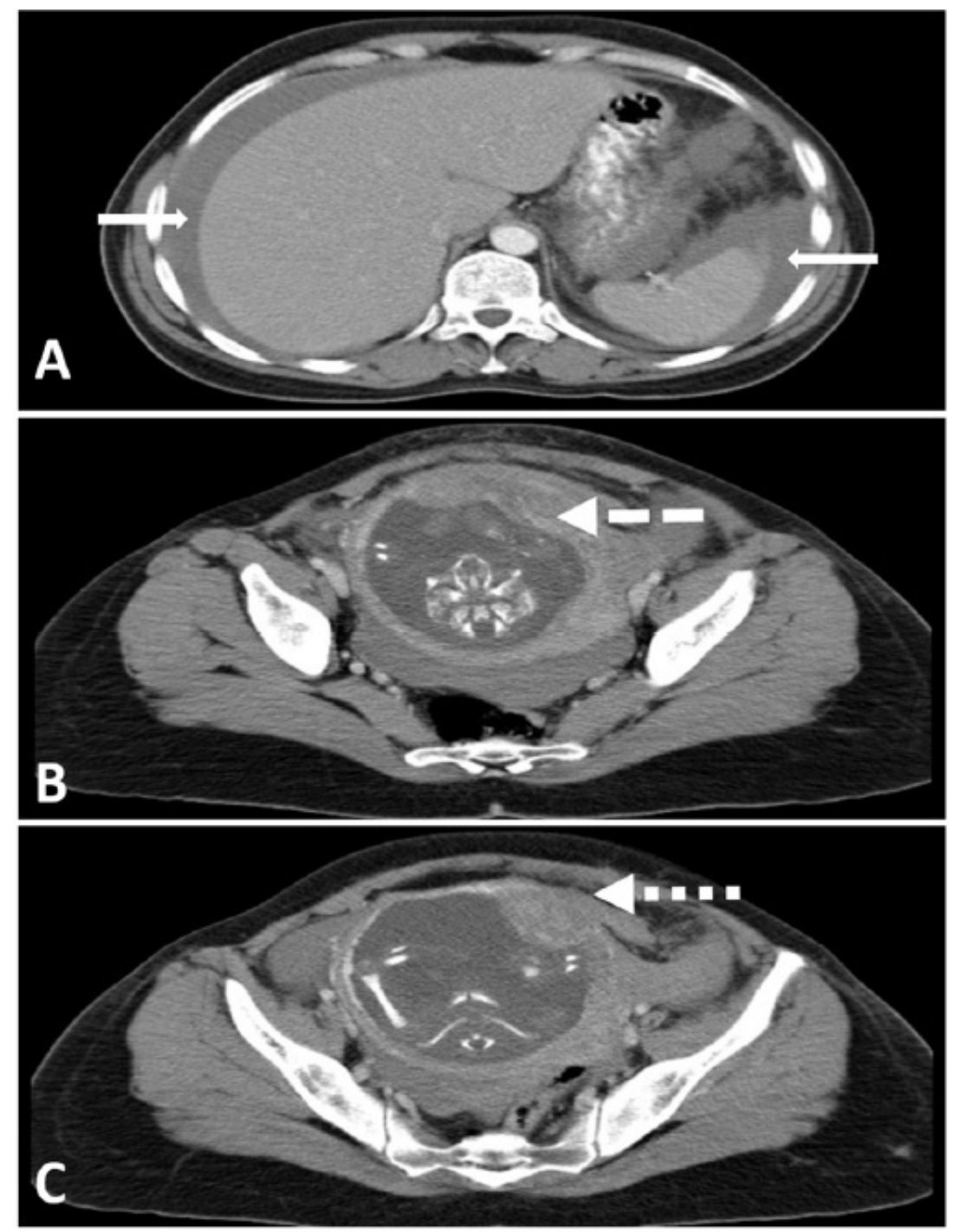

Figure 1: CT-scan of the abdomen and pelvis showing signs of uterine rupture due to fundal placenta percreta; A) Hemoperitoneum around the liver and spleen (solid white arrows); B) Fundal insertion of the placenta (dashed white arrow); C) Placental invasion of the myometrium at the left fundus level (dotted white arrow). 
tors for previa-AIP. The incidence of previa-AIP increases exponentially with increasing number of $C D$. It can reach up to $67 \%$ in women with previous $4 \mathrm{CD}$ or more compared to $3 \%$ in women with no previous CD [2]. Similar trend has been reported in women with non-previa AIP. Women with more than 6 previous CD had an incidence of $4.7 \%$ of non-previa accreta compared to $0.03 \%$ in women with no previous $C D$ $[2,6,7]$. In our case, the absence of placenta previa decreased the suspicion of AIP despite the presence of two previous cesarean deliveries. Findings on CT scan have pointed directly to the etiology and allowed a timely management. In fact, cases with non-previa AIP are rarely diagnosed prenatally and the vast majority will have either a postpartum retained placenta or rarely might develop focal uterine perforation, as in our case, or even uterine rupture with possible hemorrhagic catastrophes.

Little is known about the exact incidence, risk factors, best diagnostic imaging modality or the optimal management of non-previa AIP. Even when these cases were highly suspected, no clear guidelines exist concerning the best modality of prenatal management or timing and route of delivery $[3,8,9]$. A search in Medline database was done using the following terms: ["fund"” AND ("abnormal placenta"” OR placenta percreta" OR "placenta accrete" OR "placenta increta")]. The search was limited to articles published in English. The reference list of each relevant article was also searched. In total, we found 113 cases with similar clinical presentation to the present case.

CT-scan was used to orient management in only 8 cases (Table 1) [10-15]. This imaging modality is not usually used during pregnancy except in emergency situations at ED. It is considered the modality of choice owing to its availability, effectiveness and the ease of use without lengthy preparation. It is the gold-standard imaging tool used in EDs worldwide [16]. Although, during pregnancy, some obstetricians have restrictions related to radiation exposure, CT-scan can be used especially

Table 1: Characteristics and CT-Scan findings of the 9 cases of fundal placenta percreta complicated by uterine rupture.

\begin{tabular}{|c|c|c|c|c|c|c|c|}
\hline Author & $\begin{array}{l}\text { Age } \\
\text { (yo) }\end{array}$ & Parity & $\begin{array}{l}\text { GA } \\
\text { (weeks) }\end{array}$ & Risk factors & CT-scan findings & Site of rupture & Surgery \\
\hline \multirow[t]{2}{*}{$\begin{array}{l}\text { Sun, } 2016 \\
{[10]}\end{array}$} & 39 & G2P1 & 17 & -Myomectomy & $\begin{array}{l}\text { - Large mass-like high attenuation } \\
\text { irregular collection above uterus } \\
\text { - Large hemoperitoneum } \\
\text { - Suggesting rupture }\end{array}$ & $\begin{array}{l}\text { Tear of } 2 \mathrm{~cm} \text { in the } \\
\text { left cornu }\end{array}$ & NA \\
\hline & 24 & GP40 & 34 & -3 abortions & $\begin{array}{l}\text { - Large mass-like high attenuation } \\
\text { irregular collection above uterus } \\
\text { - Large hemoperitoneum } \\
\text { - Uterine wall discontinuity } \\
\text { - Suggesting rupture }\end{array}$ & $\begin{array}{l}\text { Tear of } 1.5 \mathrm{~cm} \text { in } \\
\text { the left cornu }\end{array}$ & NA \\
\hline $\begin{array}{l}\text { Rasool, } \\
2016[11]\end{array}$ & 32 & G3P1 & 28 & $\begin{array}{l}-1 C D \\
-1 D \& C\end{array}$ & - Hemoperitoneum & $\begin{array}{l}\text { Complete rupture } \\
\text { of the left cornu }\end{array}$ & Hysterectomy \\
\hline $\begin{array}{l}\text { Dahiya, } \\
2012[12]\end{array}$ & 40 & G1P0 & 19 & $\begin{array}{l}\text { - Asherman's } \\
\text { syndrome } \\
\text { - IVF }\end{array}$ & $\begin{array}{l}\text { - Hemoperitoneum } \\
\text { - Weakening of myometrium } \\
\text { at the left fundus }\end{array}$ & $\begin{array}{l}\text { Large uterine } \\
\text { fundal defect }\end{array}$ & Hysterectomy \\
\hline \multirow{2}{*}{$\begin{array}{l}\text { Martinez- } \\
\text { Garza, } \\
2012[13]\end{array}$} & 28 & G1P0 & 20 & $\begin{array}{l}\text { - Didelphys } \\
\text { uterus }\end{array}$ & - Hemoperitoneum & $\begin{array}{l}\text { Fundus of hemi- } \\
\text { uterus }\end{array}$ & Hysterectomy \\
\hline & 20 & G2P0 & NA & $\begin{array}{l}\text { - } 1 \text { abortion } \\
\text { - Bicornuate } \\
\text { uterus }\end{array}$ & $\begin{array}{l}\text { - Hemoperitoneum } \\
\text { - Free fetus in the abdomen }\end{array}$ & $\begin{array}{l}\text { Left uterine } \\
\text { horn }\end{array}$ & $\begin{array}{l}\text { Removal } \\
\text { of the } \\
\text { horn }\end{array}$ \\
\hline $\begin{array}{l}\text { Sant, } \\
2012[14]\end{array}$ & 30 & G2P0 & 21 & $\begin{array}{l}-1 \text { TOF } \\
\text { - PID } \\
\text { - Bicornuate } \\
\text { uterus }\end{array}$ & - Hemoperitoneum & Right uterine horn & $\begin{array}{l}\text { Removal } \\
\text { of the } \\
\text { horn }\end{array}$ \\
\hline $\begin{array}{l}\text { Son, } 2006 \\
{[15]}\end{array}$ & 35 & G6P2 & 8 & $\begin{array}{l}-2 \text { NVD } \\
-3 \text { D\&C }\end{array}$ & $\begin{array}{l}-6 \times 5 \mathrm{~cm} \text { bulging vascular mass } \\
\text { on left uterine corneal portion }\end{array}$ & $\begin{array}{l}4 \times 3 \mathrm{~cm} \text { cystic } \\
\text { lesion on the } \\
\text { left fundus }\end{array}$ & Hysterectomy \\
\hline $\begin{array}{l}\text { The } \\
\text { present } \\
\text { case }\end{array}$ & 33 & G3P2 & 21 & $-2 C D$ & $\begin{array}{l}-2 \times 2 \mathrm{~cm} \text { bulging vascular mass } \\
\text { through the left fundal area } \\
\text { - Hemoperitoneum }\end{array}$ & $\begin{array}{l}3 \times 2 \mathrm{~cm} \text { dent on } \\
\text { the left antero- } \\
\text { lateral side of the } \\
\text { fundus }\end{array}$ & Hysterectomy \\
\hline
\end{tabular}

Abbreviations: CD: Cesarean Delivery; D\&C: Dilatation and Curettage; G: Gravida; GA: Gestational Age; IVF: In-Vitro Fertilization; NA: Not Available; NVD: Normal Vaginal Delivery; P: Para; PID: Pelvic Inflammatory Disease; TOF: Termination of Pregnancy. 
when benefits outweigh risks to evaluate non-obstetric causes of acute abdomen with excellent accuracy [17]. In 3 out of 8 cases, CT-scan identified the site of rupture as in our case, however, in the 5 remaining cases, there were indirect signs such as floating fetus in the cavity, hemoperitoneum and high attenuation collection near the uterus.

The presence of placenta previa in patients with previous cesarean deliveries raises the suspicion of AIP and these cases are referred to specialized centers for assessment of abnormal placentation. Whereas, in non-previa (fundal-located placentae), AIP is usually not suspected and hence such patients might experience serious adverse outcome. In patients with previous uterine surgical intervention (including cesarean delivery), meticulous assessment of placentae, irrespective of their location, should be performed searching for $a b$ normal sonographic features or vascular patterns that are usually associated with AIP [18].

In conclusion, AIP rate will continue to escalate in parallel with the ever-increasing rate of $C D$. More awareness, enhanced imaging accuracy and better surgical experience with handling of previa-associated AIP have resulted in curbing hemorrhagic complication rates. No large series or studies exist to date to guide on the diagnosis and the optimal management of non-previa AIP both in the antenatal or peripartum periods. Acknowledgement of increased risk for non-previa. AIP in association with any uterine surgical intervention or anomaly, searching for the common sonographic features and abnormal hypervascularity pattern during first or second trimester and judicious intervention appropriate with the family planning of the patient might be of value in ameliorating the dismal outcome of these serious cases.

\section{Funding}

This research did not receive any specific grant from funding agencies in the public, commercial, or not-forprofit sectors.

\section{Conflict of Interest}

The Authors declare that there is no conflict of interest.

\section{References}

1. Tantbirojn P, Crum CP, Parast MM (2008) Pathophysiology of placenta creta: The role of decidua and extravillous trophoblast. Placenta 29: 639-645.

2. Silver RM, Landon MB, Rouse DJ, Leveno KJ, Spong CY, et al. (2006) Maternal morbidity associated with multiple repeat cesarean deliveries. Obstet Gynecol 107: 1226-1232.

3. Belfort MA (2010) Placenta accreta. Am J Obstet Gynecol 203: 430-439.

4. Comstock CH (2005) Antenatal diagnosis of placenta accreta: A review. Ultrasound Obstet Gynecol 26: 89-96.

5. Kinoshita T, Ogawa K, Yasumizu T, Kato J (1996) Spontaneous rupture of the uterus due to placenta percreta at 25-weeks' gestation: A case report. J Obstet Gynaecol Res 22: $125-128$.

6. Miller DA, Chollet JA, Goodwin TM (1997) Clinical risk factors for placenta previa-placenta accreta. Am J Obstet Gynecol 177: 210-214.

7. Marshall NE, Fu R, Guise J-M (2011) Impact of multiple cesarean deliveries on maternal morbidity: a systematic review. Am J Obstet Gynecol 205: 262.e1-262.e8.

8. (2012) Committee opinion no. 529: placenta accreta. Obstet Gynecol 120: 207-211.

9. Jauniaux E, Bhide A, Kennedy A, Woodward P, Hubinont C, et al. (2018) FIGO consensus guidelines on placenta accreta spectrum disorders: Prenatal diagnosis and screening. Int J Gynaecol Obstet 140: 274-280.

10. Sun JN, Zhang BL, Yu HY, Zhang Q (2016) Spontaneous uterine rupture due to placenta percreta during pregnancy. Am J Emerg Med 34: 1918.e1-1918.e3.

11. Rasool M, Masroor I, Shakoor S, Munim S (2016) Spontaneous uterine rupture at 28 weeks: A case report. J Pak Med Assoc 66: 898-900.

12. Dahiya P, Nayar KD, Gulati AJS, Dahiya K (2012) Placenta Accreta Causing Uterine Rupture in Second Trimester of Pregnancy after in vitro Fertilization: A Case Report. J Reprod Infertil 13: 61-63.

13. Martinez-Garza PA, Robles-Landa LP, Roca-Cabrera M, Visag-Castillo VJ, Reyes-Espejel L, et al. (2012) Spontaneous uterine rupture: report of two cases. Cir Cir 80: 8185.

14. Sant CLH, Andersen PE (2012) Misdiagnosed uterine rupture of an advanced cornual pregnancy. Case Rep Radiol 2012: 289103.

15. Son G, Kwon J, Cho H, Kim S, Yoon B, et al. (2007) A case of placenta increta presenting as delayed postabortal intraperitoneal bleeding in the first trimester. J Korean Med Sci 22: 932-935.

16. Stoker J, Van Randen A, Lameris W, Boermeester MA (2009) Imaging patients with acute abdominal pain. Radiology 253: 31-46.

17. Lazarus E, Mayo-Smith WW, Mainiero MB, Spencer PK (2007) CT in the evaluation of nontraumatic abdominal pain in pregnant women. Radiology 244: 784-790.

18. Jauniaux E, Toplis PJ, Nicolaides KH (1996) Sonographic diagnosis of a non-previa placenta accreta. Ultrasound Obstet Gynecol 7: 58-60. 